\title{
Preliminary analysis of posttraumatic stress disorder screening within specialty clinic setting for OIF/OEF veterans seeking care for neck or back pain
}

\author{
Andrew S. Dunn, DC, MEd, MS; ${ }^{1-2 *}$ Terri Julian, PhD; ${ }^{3}$ Lance R. Formolo, DC, MS; ${ }^{1}$ Bart N. Green, DC, \\ MSEd; ${ }^{4-5}$ David R. Chicoine ${ }^{2}$ \\ ${ }^{1}$ Department of Veterans Affairs (VA) Western New York Healthcare System, Buffalo VA Medical Center, Buffalo, NY; \\ ${ }^{2}$ New York Chiropractic College, Seneca Falls, NY; ${ }^{3}$ VA Western New York Healthcare System, Batavia VA Medical \\ Center, Batavia, NY; ${ }^{4}$ Department of Physical and Occupational Therapy, Chiropractic Division, Naval Medical \\ Center San Diego, Marine Corps Air Station Miramar Branch Medical Clinic, San Diego, CA; ${ }^{5}$ National University \\ of Health Sciences, Lombard, IL
}

\begin{abstract}
Escalating prevalence estimates of posttraumatic stress disorder (PTSD) among recently returning Operation Iraqi Freedom/Operation Enduring Freedom (OIF/OEF) veterans highlight the need for early detection and management for reducing chronic mental illness and disability. Because PTSD and chronic pain are common comorbid conditions among veterans, PTSD screening within specialty clinic settings addressing musculoskeletal pain may be of value. This retrospective study evaluated measures of diagnostic value for the PTSD Checklist (PCL) for a sample $(n=79)$ of OIF/OEF veterans seeking care for neck or back pain within a Department of Veterans Affairs specialty clinic. Because published accounts of optimal PCL cutoff scores vary considerably, we used receiver operating characteristic curves to identify whether the optimal PCL cutoff score for the sample differed from a conventional cutoff score of 50. A clinical psychologist experienced in diagnosing and managing PTSD confirmed the diagnosis of PTSD for 37 veterans through a review of clinical records. The prevalence of diagnosed PTSD was $46.8 \%$, with an optimal PCL cutoff score of 44. These findings may guide future research and influence clinical practice regarding PTSD screening for recently returning veterans with chronic pain.
\end{abstract}

Key words: back pain, health psychology, musculoskeletal phenomena, neck pain, neural physiological phenomena, Operation Enduring Freedom, Operation Iraqi Freedom, posttraumatic stress disorder, rehabilitation, sensitivity, specificity, veterans.

\section{INTRODUCTION}

Posttraumatic stress disorder (PTSD) is defined by behavioral symptoms of reexperiencing, avoidance, and autonomic hyperarousal stemming from exposure to a threatening traumatic event that resulted in a response of fear, helplessness, or horror [1]. The criteria for the diagnosis of PTSD specify that symptoms must be present for more than 4 weeks and cause distress or impairment regarding social, occupational, or other areas of functioning [1]. In addition to the effect PTSD has on individual health, quality of life, general function, and healthcare service use, the healthcare system and society as a whole are considerably

Abbreviations: $\mathrm{CI}=$ confidence interval, $\mathrm{OEF}=$ Operation Enduring Freedom, OIF $=$ Operation Iraqi Freedom, PCL = PTSD Checklist, PC-PTSD = primary care PTSD, PTSD = posttraumatic stress disorder, ROC = receiver operating characteristic, VA = Department of Veterans Affairs, VAWNYHS = VA Western New York Healthcare System.

* Address all correspondence to Andrew S. Dunn, DC, MEd, MS; VA Western New York Healthcare SystemChiropractic, 3495 Bailey Ave, Buffalo, NY 14215; 716-8628543; fax: 716-862-7248. Email: Andrew.dunn@va.gov DOI:10.1682/JRRD.2010.05.0104 
burdened economically [2-5]. Among returning Operation Iraqi Freedom (OIF)/Operation Enduring Freedom (OEF) Veterans, most prevalence estimates of PTSD range from 5 to 20 percent and are generally higher among those seeking treatment [6]. The prevalence and costs associated with PTSD establish a need for detecting PTSD early and accurately and implementing evidence-based interventions to prevent chronic mental illness and disability [7].

Studies have also reported that a substantial percentage of OIF/OEF and Persian Gulf war veterans experience chronic pain following their period of Active Duty [8-10]. Mounting evidence exists within the scientific literature regarding the co-occurrence of and the relationship between PTSD and chronic pain [11-18]. Otis et al. has published a comprehensive summary of theoretical models, including mutual maintenance and shared vulnerability, underlying comorbid chronic pain and PTSD [14]. They report that chronic pain and PTSD frequently co-occur, they increase the symptom severity of either condition, and their interaction may negatively affect the management for either disorder [14]. Authors suggest that clinicians who evaluate and manage chronic pain or PTSD should diagnostically assess for both disorders [13-14].

Despite the use of the four-item primary care PTSD (PC-PTSD) screening tool within Department of Veterans Affairs (VA) primary care clinics [19-20], the diagnosis of PTSD is reportedly often missed within primary care settings [21]. Based upon high rates of mutually occurring PTSD and chronic pain, patients with musculoskeletal pain may have PTSD that has not been recognized. Thus, specialty clinic settings addressing musculoskeletal pain may provide additional opportunities for recognizing PTSD for appropriate referral for clinical management. The screening instrument used within this study was the PTSD Checklist (PCL) for military experiences [22]. A conventional cutoff score of 50 had been used for screening veterans within this clinic consistent with work done by Weathers et al. [22].

Because operating characteristics of the PCL vary considerably across populations and settings, use of a conventional cutoff score could lead to a PCL misapplication [23]. For this reason, this study specifically aimed to determine whether the optimal PCL cutoff score differed from 50 for a sample of OIF/OEF veterans seeking treatment for neck or back pain within a specialty clinic addressing musculoskeletal pain.

\section{METHODS}

\section{Study Population}

The sampling frame was represented by OIF/OEF veterans with a chief complaint of neck pain or back pain consecutively referred to the VA Western New York Healthcare System (VAWNYHS) chiropractic clinic during 12 months between January 1 and December 31, 2009, with a completed PCL at baseline. Patients were suspected of having PTSD based on the diagnosis being embedded either within the problem list or within patient encounters. A clinical psychologist experienced in diagnosing and managing PTSD in veterans reviewed the clinical records of patients with suspected PTSD to confirm the diagnosis of PTSD through the presence of one or more of the following criteria: (1) diagnostic evaluation by a licensed behavioral health professional, (2) positive PCL, (3) positive PC-PTSD screen, and (4) service-connected disability status for PTSD.

\section{Source of Data}

Demographic data were extracted from the clinical record within the VA Computerized Patient Record System and entered into a secure, prospectively maintained quality assurance data set at the initial consultation. Pain severity (based upon a 0-10 verbal numeric rating scale) and the chronicity of presenting neck or back pain complaints (>6 months) were obtained during the patient's history of chief complaint. The PCL is a 17-item rating instrument developed at the National Center for PTSD, with scores ranging from 17 to 85 [22]. It is one of the most widely used self-report instruments for assessing PTSD [23-24]. Published accounts of PTSD screening for both civilian and military versions of the PCL, with variations in populations, settings, reference standards, research methods, and optimality criteria, have reported optimal cutoff scores ranging from 28 to 60 [22,25-37]. Each patient was given the PCL during consultation, with an opportunity to complete in a self-reported manner so that we could gain a raw score measure of PTSD symptom severity.

\section{Statistical Analysis}

We used descriptive statistics to express the demographic characteristics of the sample. Comparative analysis of the characteristics of the subsets of OIF/OEF veterans with and without PTSD was performed with $t$-tests or chisquare, as appropriate. We generated receiver operating characteristic (ROC) curves to examine the range of PCL 
values, with the confirmed diagnosis of PTSD serving as the reference standard. Measures of diagnostic value included sensitivity (true positive rate), specificity (true negative rate), accuracy (proportion of cases correctly diagnosed), the kappa statistic (chance-corrected measure of agreement with the reference standard) [38-39], and the Youden index (maximum vertical distance from the curve to the chance line) [40]. For this study, the decision threshold for optimality centered on the Youden index (sensitivity - [1 - specificity]) that represents the point on the ROC curve furthest from chance [40-41]. Perkins and Schisterman advocate the use of the Youden index to determine the optimal cutoff that mathematically maximizes the overall correct classification rates [41]. The significance level was set at $p<0.05$. We conducted analyses using JMP 5.1 (SAS Institute; Cary, North Carolina).

\section{RESULTS}

We found 42 OIF/OEF veterans with suspected PTSD based on the diagnosis embedded either within the problem list or within patient encounters. A clinical record review by our clinical psychologist confirmed a diagnosis of PTSD for 37 of those 42 veterans based on at least one form, and often multiple forms, of diagnosis validation (diagnostic evaluation by a licensed behavioral health professional, positive PCL, or positive PC-PTSD screen). Additionally, 36 of the 37 with a confirmed diagnosis of PTSD had a service-connected disability for PTSD that was assigned following diagnostic evaluation within the compensation and pension process. The five veterans with suspected PTSD that was not confirmed through clinical records review were subsequently included in the subset of those without PTSD. Analysis was then performed for a sample of 79 OIF/OEF veterans consisting of 37 with PTSD and 42 without PTSD.

Comparisons of the demographic characteristics of the subsets of OIF/OEF veterans with and without PTSD are presented in Table 1. No significant differences were found between the subsets regarding pain severity, the chronic nature of the pain complaints, or the percentage of service-connected disability associated with the chief complaint of neck or back pain. Significant differences were found between the subsets in terms of both the level of overall service-connected disability and the PCL scores. The OIF/OEF veterans with PTSD had a mean service-connected disability percentage related to PTSD of 34.05 percent (95\% confidence interval [CI], 24.4543.66) (not shown in Table 1), while none of the sample without PTSD had a service-connected disability percentage related to PTSD.

The prevalence of PTSD among the OIF/OEF veterans was 46.8 percent (37/79), with a mean value of the PCL of 43.47 (95\% CI, 39.14-47.80). The area under the ROC curve was 0.88 (95\% CI, 0.78-0.94). Based on having the highest value of the Youden index (0.64), 44 was determined to be the optimal PCL cutoff score for this sample representing that point on the ROC curve furthest from the chance line. The cutoff score of 44 also had the highest

Table 1.

Comparison of characteristics for Operation Iraqi Freedom/Operation Enduring Freedom veterans with $(n=37)$ and without $(n=42)$ posttraumatic stress disorder (PTSD).

\begin{tabular}{|c|c|c|c|}
\hline Characteristic & $\begin{array}{c}\text { With PTSD } \\
\text { n (\%) or Mean (95\% CI) }\end{array}$ & $\begin{array}{c}\text { Without PTSD } \\
\text { n (\%) or Mean }(95 \% \text { CI) }\end{array}$ & $p$-Value \\
\hline Male & 32 (86.49) & $33(78.57)$ & 0.35 \\
\hline Age & 30 (27.59-32.41) & 31.21 (28.67-33.76) & 0.49 \\
\hline BMI $\left(\mathrm{kg} / \mathrm{m}^{2}\right)$ & 28.97 (27.25-30.69) & 27.65 (26.22-29.09) & 0.23 \\
\hline Depression & $12(32.43)$ & $11(26.19)$ & 0.54 \\
\hline PCL Score (17-85) & 56.65 (51.83-61.46) & $31.86(27.10-36.61)$ & $<0.001$ \\
\hline Chronic Pain (>6 mo) & 33 (89.19) & $40(95.24)$ & 0.31 \\
\hline Baseline Pain Severity $(0-10)$ & $5.16(4.38-5.95)$ & $4.95(4.24-5.66)$ & 0.69 \\
\hline \multicolumn{4}{|l|}{ Service-Connected Disability } \\
\hline Overall & 47.03 (36.97-57.09) & $26.19(16.58-35.80)$ & 0.003 \\
\hline Neck or Back & $5.68(2.68-8.67)$ & $10.0(4.85-15.15)$ & 0.16 \\
\hline
\end{tabular}


values of both kappa (0.64) and accuracy (0.82), with high levels of both sensitivity (0.81) and specificity (0.83). The table of associated values and the corresponding ROC curve are presented in Table 2 and the Figure, respectively.

\section{DISCUSSION}

The 46.8 percent prevalence of PTSD among OIF/ OEF veterans within this study far exceeds the estimates by 12 percent within VA or community-based primary care settings and as high as 8 percent within the general population [21,42-44]. The prevalence of PTSD was reportedly 10 percent among veterans from the first Gulf war [28] and 14 percent among male Vietnam era veterans [45]. Methodological factors have reportedly varied prevalence estimates considerably for combat-related PTSD among U.S. military veterans from Vietnam through present theaters of combat [5]. Estimates of PTSD prevalence among OIF/OEF veterans generally range from 5 to 20 percent [6-7,19,46-47]. The prevalence of PTSD in this sample of OIF/OEF veterans is consistent with recent published accounts for veterans within rehabilitation settings and is of significant concern based on the implications of rapidly approaching medical and psychological needs for this population [48-49]. Within a VA Polytrauma Network Site providing specialized rehabilitation services for severely injured veterans, the prevalence of PTSD among a sample of OIF/OEF veterans has been reported to be 68.2 percent with considerable chronic pain and postconcussive symptom comorbidity [49].

Several possible explanations exist for the 46.8 percent prevalence of PTSD in the OIF/OEF sample in this study. Among recently returning veterans, an increase in the prevalence of PTSD has been associated with multiple factors, including (1) exposure to combat [47], (2) battle versus nonbattle injuries [50], (3) increase of deployment intensity and duration [51], and (4) blast injuries as opposed to other mechanisms of injury [9]. Elements of modern body armor, improved battlefield healthcare, and rapid medical evacuation have helped decrease combat-related mortality with an associated increase in the percentage of soldiers surviving severe traumatic injuries [49,52-53]. Based on the previously discussed relationship between chronic pain and PTSD, one would expect that the prevalence of PTSD would be high within VA specialty clinic settings that evaluate and manage musculoskeletal pain. Another possibility is that $\mathrm{OIF} / \mathrm{OEF}$ veterans are more willing to self-report

Table 2.

Measures of diagnostic value of Posttraumatic Stress Disorder Checklist for sample Operation Iraqi Freedom/Operation Enduring Freedom veterans $(n=79)$. Bold values identify optimal cutoff value of each measure.

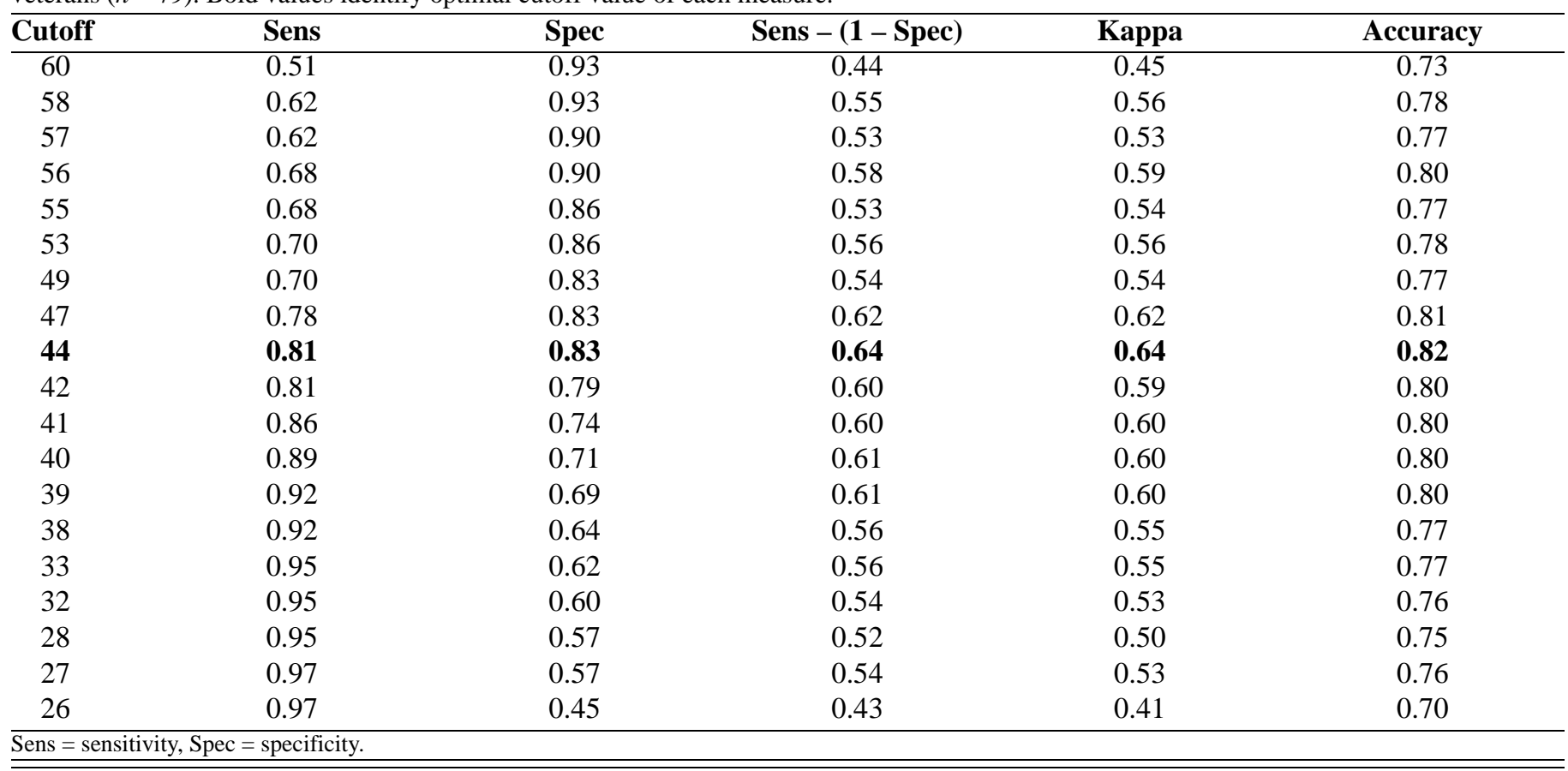




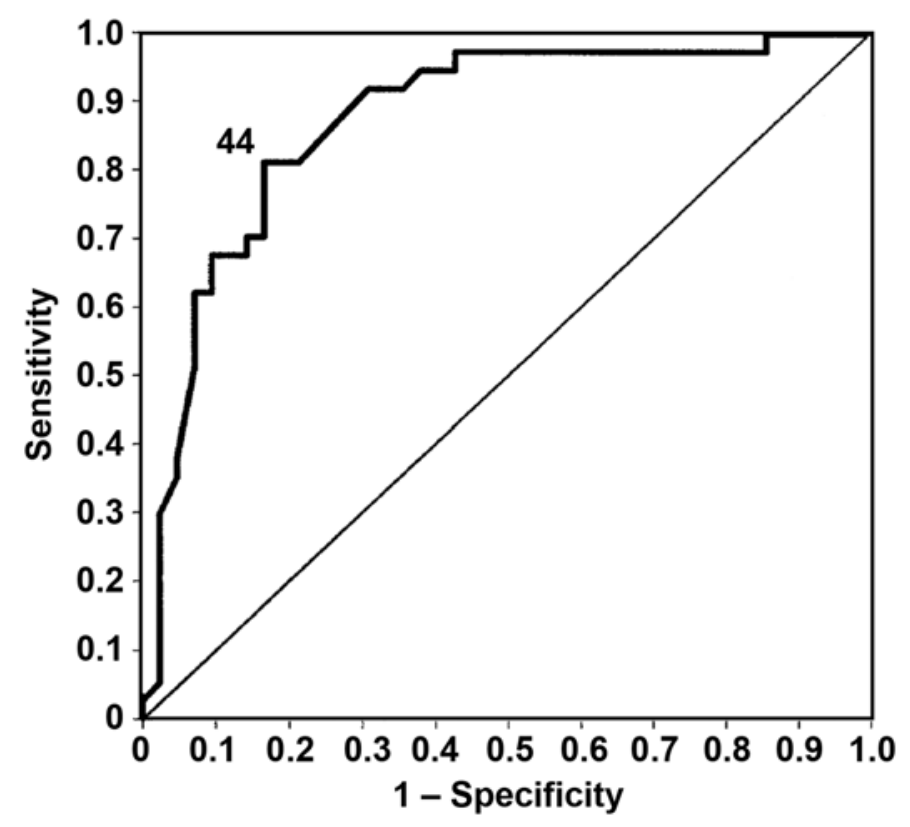

Figure.

Receiver operating characteristic curve (ROC) for $(n=79)$ Operation Iraqi Freedom/Operation Enduring Freedom, veterans with $46.8 \%$ posttraumatic stress disorder prevalence. $44=$ optimal cutoff score that represents point on ROC curve farthest from chance line.

symptoms of PTSD than veterans of previous conflicts and generations. Finally, increased clinical awareness and screening efforts are likely identifying PTSD symptoms among OIF/OEF veterans that might have gone undetected in veterans from previous conflicts.

Studies have demonstrated both high levels of PTSD symptom severity among patients with chronic pain [54] and high rates of chronic pain among patients with PTSD [16-17,55]. PTSD symptom severity has been associated with poorer health functioning among OIF/OEF veterans [56-57]. Additionally, PTSD symptom expression has been shown to differ between pain and pain-free populations [58]. Shipherd et al. suggest that healthcare providers dedicated to pain management should be aware of the prevalence and potential impact of behavioral health disorders, including PTSD, on clinical outcomes [59]. While further investigation is needed to understand the impact that PTSD has, alone or in combination with other behavioral health disorders, on conservative forms of pain management, providers of pain management for musculoskeletal conditions need to be knowledgeable about PTSD, to incorporate screening procedures to recognize PTSD, and to establish multidisciplinary relationships with behavioral health clinicians to facilitate the referral process for patients, as appropriate. We believe that significant improvements in chronic pain for patients with comorbid PTSD will be difficult to attain without appropriate behavioral healthcare being provided.

While a series of measures of diagnostic values for the PCL were presented to enhance interpretation of the data, we attempted to justify the use of the Youden index as the primary basis for determining the optimal PCL cutoff score. While both accuracy and kappa are reported, they can be misleading because of their high level of dependence on disease prevalence, making them potentially less than ideal determinants of optimal cutoff scores [60-62]. With the methodology applied, the current findings suggest that a PCL cutoff score of 50 was too high for this sample.

Bliese et al. reported on variations in optimal PCL cutoff scores based on different settings, data collection procedures, and populations used within validation studies [35]. Terhakopian et al. stressed that determining the ideal PCL cutoff score should be a function of the purpose of the measure (clinical screening tool vs estimation of population prevalence) and the population prevalence of PTSD [63]. Lower cutoff scores may also be of value in detecting PTSD on screening instruments among recent military returnees who may have a stigma against reporting PTSD symptoms and other psychological problems [46]. One can reasonably speculate that PCL cutoffs within a sample of veterans seeking care for musculoskeletal complaints would fall between the lowest PCL scores associated within primary care or Active Duty samples (stigma-related concerns about admitting behavioral health problems resulting in underreporting) and the highest PCL scores associated with populations seeking treatment within behavioral health settings (less stigma-related concerns because they are seeking or already receiving behavioral healthcare) [35].

This retrospective study had a number of limitations. While sufficient for analysis, the sample size was relatively small and the findings should not be generalized outside of the study sample. The OIF/OEF veteran patients within this study were seen within a specialty clinic setting that was subject to gatekeeper referral bias and may not fully represent veterans generally seen within other clinical settings. Additionally, analysis did not account for those undergoing treatment for PTSD and the potential influence of partially treated PTSD on PCL values. While we attempted to confirm the diagnosis of 
PTSD within the clinical record as a diagnostic reference standard, analysis lacked comparison with the Clinician Administered PTSD Scale that is considered the gold standard criterion for PTSD diagnosis [64-66]. Considerable variation in published optimal PCL cutoff scores and the preliminary findings within this study show that further research is needed.

\section{CONCLUSIONS}

We found a 46.8 percent prevalence of PTSD among this sample of OIF/OEF veterans seeking care for neck or back pain in a specialty clinic setting. Considerable variation has been reported in the operating characteristics of the PCL across populations, setting, and research methods. While a conventional PCL cutoff score for veterans of 50 had been used for PTSD screening within this clinic, the optimal PCL cutoff score for this sample was determined to be 44 . The findings imply that future research is needed regarding PTSD screening for OIF/ OEF veterans with chronic pain. In terms of conservative pain management, a high prevalence of PTSD and the interrelationships between PTSD and chronic pain may represent a considerable clinical challenge for both patients and providers, highlighting the significance of identifying optimal collaborative management strategies for this unique patient population.

\section{ACKNOWLEDGMENTS}

\section{Author Contributions:}

Study concept and design: A. S. Dunn, T. Julian, B. N. Green. Acquisition of data: A. S. Dunn, L. R. Formolo.

Analysis and interpretation of data: A. S. Dunn, T. Julian, B. N. Green, D. R. Chicoine.

Drafting manuscript: A. S. Dunn, T. Julian, L. R. Formolo, B. N. Green, D. R. Chicoine.

Critical revision of manuscript for important intellectual content: T. Julian. Study supervision: A. S. Dunn.

Financial Disclosure: The authors have declared that no competing interests exist.

Funding/Support: This material is the result of work supported with resources and the use of facilities at VAWNYHS, Buffalo, New York.

Institutional Review: The study was approved through the VAWNYHS Research and Development Committee and Institutional Review Board.

Participant Follow-Up: The authors do not plan to inform participants of the publication of this study.
Disclaimer: The views expressed in this article are those of the authors and do not reflect the official policy or position of the Department of the Navy, Department of Defense, or U.S. Government.

\section{REFERENCES}

1. American Psychiatric Association. Diagnostic and statistical manual of mental disorders. 4th ed. Text revision. Washington (DC): American Psychiatric Press; 2000.

2. Hidalgo RB, Davidson JR. Posttraumatic stress disorder: Epidemiology and health-related considerations. J Clin Psychiatry. 2000;61(Suppl 7):5-13. [PMID: 10795604$]$

3. Priebe S, Matanov A, Jankovi Gavrilovi J, McCrone P, Ljubotina D, Knezevi G, Kucukali A, Franciskovi T, Schützwohl M. Consequences of untreated posttraumatic stress disorder following war in former Yugoslavia: Morbidity, subjective quality of life, and care costs. Croat Med J. 2009;50(5):465-75. [PMID: 19839070] DOI:10.3325/cmj.2009.50.465

4. McFarlane AC. The long-term costs of traumatic stress: Intertwined physical and psychological consequences. World Psychiatry. 2010;9(1):3-10. [PMID: 20148146]

5. Richardson LK, Frueh BC, Acierno R. Prevalence estimates of combat-related post-traumatic stress disorder: Critical review. Aust N Z J Psychiatry. 2010;44(1):4-19. [PMID: 20073563] DOI:10.3109/00048670903393597

6. Ramchand R, Schell TL, Karney BR, Osilla KC, Burns RM, Caldarone LB. Disparate prevalence estimates of PTSD among service members who served in Iraq and Afghanistan: Possible explanations. J Trauma Stress. 2010; 23(1):59-68. [PMID: 20135699]

7. Seal KH, Bertenthal D, Miner CR, Sen S, Marmar C. Bringing the war back home: Mental health disorders among 103,788 U.S. veterans returning from Iraq and Afghanistan seen at Department of Veterans Affairs facilities. Arch Intern Med. 2007;167(5):476-82. [PMID: 17353495] DOI:10.1001/archinte.167.5.476

8. Gironda RJ, Clark ME, Massengale JP, Walker RL. Pain among veterans of Operations Enduring Freedom and Iraqi Freedom. Pain Med. 2006;7(4):339-43. [PMID: 16898945] DOI:10.1111/j.1526-4637.2006.00146.x

9. Sayer NA, Chiros CE, Sigford B, Scott S, Clothier B, Pickett T, Lew HL. Characteristics and rehabilitation outcomes among patients with blast and other injuries sustained during the Global War on Terror. Arch Phys Med Rehabil. 2008; 89(1):163-70. [PMID: 18164349] DOI:10.1016/j.apmr.2007.05.025

10. Kang HK, Mahan CM, Lee KY, Magee CA, Murphy FM. Illnesses among United States veterans of the Gulf War: A population-based survey of 30,000 veterans. J Occup Environ 
Med. 2000;42(5):491-501. [PMID: 10824302]

DOI:10.1097/00043764-200005000-00006

11. Kulich RJ, Mencher P, Bertrand C, Maciewicz R. Comorbidity of post-traumatic stress disorder and chronic pain: Implications for clinical and forensic assessment. Curr Rev Pain. 2000;4(1):36-48. [PMID: 10998714]

12. Cox BJ, McWilliams L. Mood and anxiety disorders in relation to chronic pain: Evidence from the National Comorbidity Study. Pain Res Manag. 2002;5(Suppl A):11A.

13. Asmundson GJ, Coons MJ, Taylor S, Katz J. PTSD and the experience of pain: Research and clinical implications of shared vulnerability and mutual maintenance models. Can J Psychiatry. 2002;47(10):930-37. [PMID: 12553128]

14. Otis JD, Keane TM, Kerns RD. An examination of the relationship between chronic pain and post-traumatic stress disorder. J Rehabil Res Dev. 2003;40(5):397-406.

[PMID: 15080224$]$

DOI:10.1682/JRRD.2003.09.0397

15. Arguelles LM, Afari N, Buchwald DS, Clauw DJ, Furner S, Goldberg J. A twin study of posttraumatic stress disorder symptoms and chronic widespread pain. Pain. 2006;124(12):150-57. [PMID: 16701954$]$

16. Villano CL, Rosenblum A, Magura S, Fong C, Cleland C, Betzler TF. Prevalence and correlates of posttraumatic stress disorder and chronic severe pain in psychiatric outpatients. J Rehabil Res Dev. 2007;44(2):167-78. [PMID: 17551871] DOI:10.1682/JRRD.2006.05.0052

17. Shipherd JC, Keyes M, Jovanovic T, Ready DJ, Baltzell D, Worley V, Gordon-Brown V, Hayslett C, Duncan E. Veterans seeking treatment for posttraumatic stress disorder: What about comorbid chronic pain? J Rehabil Res Dev. 2007;44(2):153-66. [PMID: 17551870]

DOI:10.1682/JRRD.2006.06.0065

18. Defrin R, Ginzburg K, Solomon Z, Polad E, Bloch M, Govezensky M, Schreiber S. Quantitative testing of pain perception in subjects with PTSD-Implications for the mechanism of the coexistence between PTSD and chronic pain. Pain. 2008;138(2):450-59. [PMID: 18585862]

19. Prins A, Ouimette P, Kimberling R, Cameron PP, Hugelshofer DS, Shaw-Hewger J, Thrailkill A, Gusman FD, Sheikh JI. The primary care PTSD screen (PC-PTSD): Development and operating characteristics. Int J Psychiatry Clin Pract. 2004;9(1):9-14.

20. Ouimette P, Wade M, Prins A, Schohn M. Identifying PTSD in primary care: Comparison of the Primary CarePTSD screen (PC-PTSD) and the General Health Questionnaire-12 (GHQ). J Anxiety Disord. 2008;22(2):337-43. [PMID: 17383853$]$

DOI:10.1016/j.janxdis.2007.02.010

21. Magruder KM, Frueh BC, Knapp RG, Davis L, Hamner MB, Martin RH, Gold PB, Arana GW. Prevalence of posttraumatic stress disorder in Veterans Affairs primary care clinics. Gen
Hosp Psychiatry. 2005;27(3):169-79. [PMID: 15882763]

DOI:10.1016/j.genhosppsych.2004.11.001

22. Weathers FW, Litz BT, Herman DS, Huska JA, Keane TM. The PTSD Checklist (PCL): Reliability, validity, and diagnostic utility. Proceedings of the 9th Annual Meeting of the International Society for Traumatic Stress Studies; 1993 Oct; San Antonio, Texas.

23. McDonald SD, Calhoun PS. The diagnostic accuracy of the PTSD Checklist: A critical review. Clin Psychol Rev. 2010; 30(8):976-87. [PMID: 20705376] DOI:10.1016/j.cpr.2010.06.012

24. Elhai JD, Gray MJ, Kashdan TB, Franklin CL. Which instruments are most commonly used to assess traumatic event exposure and posttraumatic effects? A survey of traumatic stress professionals. J Trauma Stress. 2005;18(5): 541-45. [PMID: 16281252] DOI:10.1002/jts.20062

25. Blanchard EB, Jones-Alexander J, Buckley TC, Forneris CA. Psychometric properties of the PTSD Checklist (PCL). Behav Res Ther. 1996;34(8):669-73. [PMID: 8870294$]$ DOI:10.1016/0005-7967(96)00033-2

26. Andrykowski MA, Cordova MJ, Studts JL, Miller TW. Posttraumatic stress disorder after treatment for breast cancer: Prevalence of diagnosis and use of the PTSD ChecklistCivilian Version (PCL-C) as a screening instrument. J Consult Clin Psychol. 1998;66(3):586-90. [PMID: 9642900] DOI:10.1037/0022-006X.66.3.586

27. Forbes D, Creamer M, Biddle D. The validity of the PTSD Checklist as a measure of symptomatic change in combatrelated PTSD. Behav Res Ther. 2001;39(8):977-86.

[PMID: 11480838$]$ DOI:10.1016/S0005-7967(00)00084-X

28. Kang HK, Natelson BH, Mahan CM, Lee KY, Murphy FM. Post-traumatic stress disorder and chronic fatigue syndrome-like illness among Gulf War veterans: A populationbased survey of 30,000 veterans. Am J Epidemiol. 2003; 157(2):141-48. [PMID: 12522021] DOI:10.1093/aje/kwf187

29. Lang AJ, Laffaye C, Satz LE, Dresselhaus TR, Stein MB. Sensitivity and specificity of the PTSD Checklist in detecting PTSD in female veterans in primary care. J Trauma Stress. 2003;16(3):257-64. [PMID: 12816338]

DOI:10.1023/A:1023796007788

30. Ventureyra VA, Yao SN, Cottraux J, Note I, De Mey-Guillard C. The validation of the Posttraumatic Stress Disorder Checklist Scale in posttraumatic stress disorder and nonclinical subjects. Psychother Psychosom. 2002;71(1):47-53.

[PMID: 11740168]

DOI:10.1159/000049343

31. Walker EA, Newman E, Dobie DJ, Ciechanowski P, Katon W. Validation of the PTSD Checklist in an HMO sample of women. Gen Hosp Psychiatry. 2002;24(6):375-80. 
JRRD, Volume 48, Number 5, 2011

[PMID: 12490338]

DOI:10.1016/S0163-8343(02)00203-7

32. Cook JM, Elhai JD, Areán PA. Psychometric properties of the PTSD Checklist with older primary care patients. J Trauma Stress. 2005;18(4):371-76. [PMID: 16281234$]$ DOI:10.1002/jts.20038

33. Sherman JJ, Carlson CR, Wilson JF, Okeson JP, McCubbin JA. Post-traumatic stress disorder among patients with orofacial pain. J Orofac Pain. 2005;19(4):309-17. [PMID: 16279482]

34. Grubaugh AL, Elhai JD, Cusack KJ, Wells C, Frueh BC. Screening for PTSD in public-sector mental health settings: The diagnostic utility of the PTSD Checklist. Depress Anxiety. 2007;24(2):124-29. [PMID: 16892418] DOI:10.1002/da.20226

35. Bliese PD, Wright KM, Adler AB, Cabrera O, Castro CA, Hoge CW. Validating the primary care posttraumatic stress disorder screen and the posttraumatic stress disorder checklist with soldiers returning from combat. J Consult Clin Psychol. 2008;76(2):272-81. [PMID: 18377123] DOI:10.1037/0022-006X.76.2.272

36. Keen SM, Kutter CJ, Niles BL, Krinsley KE. Psychometric properties of PTSD Checklist in Sample of male veterans. J Rehabil Res Dev. 2008;45(3):465-74. [PMID: 18629754] DOI:10.1682/JRRD.2007.09.0138

37. Hudson SA, Beckford LA, Jackson SD, Philpot MP. Validation of a screening instrument for post-traumatic stress disorder in a clinical sample of older adults. Aging Ment Health. 2008;12(5):670-73. [PMID: 18855184] DOI:10.1080/13607860802343274

38. Landis JT, Koch GG. The measurement of observer agreement for categorical data. Biometrics. 1977;33(1):159-74. [PMID: 843571] DOI:10.2307/2529310

39. Portney LG, Watkins MP. Statistical measures of reliability and statistical measures of validity. In: Cohen M, editor. Foundations of clinical research: Application to practice. 3rd ed. Upper Saddle River (NJ): Prentice Hall; 2009. p. 585-658.

40. Youden WJ. An index for rating diagnostic tests. Cancer. 1950;3(1):32-35. [PMID: 15405679] DOI:10.1002/1097-0142(1950)3:1<32::AIDCNCR2820030106>3.0.CO;2-3

41. Perkins NJ, Schisterman EF. The inconsistency of "optimal” cutpoints obtained using two criteria based on the receiver operating characteristic curve. Am J Epidemiol. 2006;163(7):670-75. [PMID: 16410346]

DOI:10.1093/aje/kwj063

42. Stein MB, McQuaid JR, Pedrelli P, Lenox R, McCahill ME. Posttraumatic stress disorder in the primary care medical setting. Gen Hosp Psychiatry. 2000;22(4):261-69.

[PMID: 10936633] DOI:10.1016/S0163-8343(00)00080-3
43. Kessler RC, Sonnega A, Bromet E, Hughes M, Nelson CB. Posttraumatic stress disorder in the National Comorbidity Survey. Arch Gen Psychiatry. 1995;52(12):1048-60. [PMID: 7492257]

44. Narrow WE, Rae DS, Robins LN, Regier DA. Revised prevalence estimates of mental health disorders in the United States: Using a clinical significance criterion to reconcile 2 surveys' estimates. Arch Gen Psychiatry. 2002; 59:115-23. [PMID: 11825131] DOI:10.1001/archpsyc.59.2.115

45. Schlenger WE, Kulka RA, Fairbank JA, Hough RL, Jordan BK, Marmar CR, Weiss DS. The prevalence of post-traumatic stress disorder in the Vietnam generation: A multimethod, multisource assessment of psychiatric disorder. J Trauma Stress. 1992;5(3):333-63. DOI:10.1002/jts.2490050303

46. Hoge CW, Castro CA, Messer SC, McGurk D, Cotting DI, Koffman RL. Combat duty in Iraq and Afghanistan, mental health problems, and barriers to care. N Engl J Med. 2004; 351(1):13-22. [PMID: 15229303]

DOI:10.1056/NEJMoa040603

47. Hoge CW, Auchterlonie JL, Milliken CS. Mental health problems, use of mental health services, and attrition from military service after returning from deployment to Iraq or Afghanistan. JAMA. 2006;295(9):1023-32. [PMID: 16507803]

48. Lew HL, Poole JH, Vanderploeg RD, Goodrich GL, Dekelboum S, Guillory SB, Sigford B, Cifu DX. Program development and defining characteristics of returning military in a VA Polytrauma Network Site. J Rehabil Res Dev. 2007; 44(7):1027-34. [PMID: 18075959] DOI:10.1682/JRRD.2007.05.0073

49. Lew HL, Otis JD, Tun C, Kerns RD, Clark ME, Cifu DX. Prevalence of chronic pain, posttraumatic stress disorder, and persistent postconcussive symptoms in OIF/OEF veterans: Polytrauma clinical triad. J Rehabil Res Dev. 2009; 46(6):697-702. [PMID: 20104399] DOI:10.1682/JRRD.2009.01.0006

50. MacGregor AJ, Shaffer RA, Dougherty AL, Galarneau MR, Raman R, Baker DG, Lindsay SP, Golomb BA, Corson KS. Psychological correlates of battle and nonbattle injury among Operation Iraqi Freedom veterans. Mil Med. 2009;174(3):224-31. [PMID: 19354083]

51. Shen YC, Arkes J, Pilgrim J. The effects of deployment intensity on post-traumatic stress disorder: 2002-2006. Mil Med. 2009;174(3):217-23. [PMID: 19354082]

52. Lew HL. Rehabilitation needs of an increasing population of patients: Traumatic brain injury, polytrauma, and blastrelated injuries. J Rehabil Res Dev. 2005;42(4):xiii-xvi.

[PMID: 16320135]

DOI:10.1682/JRRD.2005.01.0124

53. Clark ME, Blair MJ, Buckenmaier CC 3rd, Gironda RJ, Walker RL. Pain and combat injuries in soldiers returning from Operations Enduring Freedom and Iraqi Freedom: 
Implications for research and practice. J Rehabil Res Dev. 2007;44(2):179-94. [PMID: 17551872]

DOI:10.1682/JRRD.2006.05.0057

54. Sherman JJ, Turk DC, Okifuji A. Prevalence and impact of posttraumatic stress disorder-like symptoms on patients with fibromyalgia syndrome. Clin J Pain. 2000;16(2):127-34.

[PMID: 10870725$]$ DOI:10.1097/00002508-200006000-00006

55. Beckham JC, Crawford AL, Feldman ME, Kirby AC, Hertzberg MA, Davidson JR, Moore SD. Chronic posttraumatic stress disorder and chronic pain in Vietnam combat veterans. J Psychosom Res. 1997;43(4):379-89.

[PMID: 9330237]

DOI:10.1016/S0022-3999(97)00129-3

56. Vasterling JJ, Schumm J, Proctor SP, Gentry E, King DW, King LA. Posttraumatic stress disorder and health functioning in a non-treatment-seeking sample of Iraq war veterans: A prospective analysis. J Rehabil Res Dev. 2008;45(3): 347-58. [PMID: 18629744] DOI:10.1682/JRRD.2007.05.0077

57. Jakupcak M, Luterek J, Hunt S, Conybeare D, McFall M. Postraumatic stress and its relationship to physical health functioning in a sample of Iraq and Afghanistan war veterans seeking postdeployment VA health care. J Nerv Ment Dis. 2008;196(5):425-28. [PMID: 18477887]

DOI:10.1097/NMD.0b013e31817108ed

58. Pagé GM, Kleiman V, Asmundson GJ, Katz J. Structure of posttraumatic stress disorder symptoms in pain and painfree patients scheduled for major surgery. J Pain. 2009; 10(9):984-91. [PMID: 19632159] DOI:10.1016/j.jpain.2009.03.011

59. Shipherd JC, Beck JG, Hamblen JL, Lackner JM, Freeman JB. A preliminary examination of treatment for posttraumatic stress disorder in chronic pain patients: A case study. J Trauma Stress. 2003;16(5):451-57. [PMID: 14584629] DOI:10.1023/A:1025754310462

60. Le CT. A solution for the most basic optimization problem associated with an ROC curve. Stat Methods Med Res. 2006;15(6):571-84. [PMID: 17260924$]$ DOI:10.1177/0962280206070637

61. Alberg AJ, Park JW, Hager BW, Brock MV, Diener-West M. The use of "overall accuracy” to evaluate the validity of screening or diagnostic tests. J Gen Intern Med. 2004; 19(5 Pt 1):460-65. [PMID: 15109345]

DOI:10.1111/j.1525-1497.2004.30091.X

62. Zweig MH, Campbell G. Receiver-operating characteristic (ROC) plots: A fundamental evaluation tool in clinical medicine. Clin Chem. 1993;39(4):561-77. [PMID: 8472349]

63. Terhakopian A, Sinaii N, Engel CC, Schnurr PP, Hoge CW. Estimating population prevalence of posttraumatic stress disorder: An example using the PTSD Checklist. J Trauma Stress. 2008;21(3):290-300. [PMID: 18553416] DOI:10.1002/jts.20341

64. Blake DD, Weathers FW, Nagy LM, Kaloupek DG, Klauminzer G, Charney DS, Keane TM. A clinician rating scale for assessing current and lifetime PTSD: The CAPS-1. Behav Ther. 1990;13:187-88.

65. Blake DD, Weathers FW, Nagy LM, Kaloupek DG, Gusman FD, Charney DS, Keane TM. The development of a ClinicianAdministered PTSD Scale. J Trauma Stress. 1995;8(1):75-90. [PMID: 7712061]

DOI:10.1002/jts.2490080106

66. Weathers FW, Keane TM, Davidson JR. Clinician-administered PTSD scale: A review of the first ten years of research. Depress Anxiety. 2001;13(3):132-56. [PMID: 11387733] DOI:10.1002/da.1029

Submitted for publication May 31, 2010. Accepted in revised form December 6, 2010.

This article and any supplementary material should be cited as follows:

Dunn AS, Julian T, Formolo LR, Green BN, Chicoine DR. Preliminary analysis of posttraumatic stress disorder screening within specialty clinic setting for OIF/OEF veterans seeking care for neck or back pain. J Rehabil Res Dev. 2011;48(5):493-502.

DOI:10.1682/JRRD.2010.05.0104

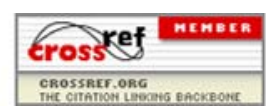


